\title{
Comparative study of acylated ghrelin levels in obese diabetes mellitus type 2 and lean diabetes mellitus type 2 female aged 30-45.
}

1. M.Phil (Physiology) Senior Demonstrator Physiology Fatima Memorial Medical and Dental College.

2. Ph.D (Physiology)

Research Supervisor IMMB University of Lahore.

3. M.Phil (Physiology)

Associate Professor Physiology

Fatima Memorial Medical and Dental College.

4. MBBS, FCPS (Surgery)

Associate Professor of Surgery

Ameer-ud-din Medical College,

PGMI,

General Hospital, Lahore.

Correspondence Address:

Dr. Zaheer lqbal Sheikh

Fatima Memorial Medical and Dental

College.

doczs2012@hotmail.com

Article received on:

20/01/2020

Accepted for publication:

05/03/2020

\section{Zaheer Iqbal Sheikh', Amna Rashid Tariq², Amer Shoaib ${ }^{3}$, Saeed Mahmood}

ABSTRACT... Objectives: To critically analyze the concentration of Acylated ghrelin and its comparative level between lean and obese type two Diabetes Mellitus female patients aged Thrity-fourty five. Study Design: Cohort study design. Setting: Department of Endocrinology, Lahore General Hospital, Lahore and Sheikh Zayad Hospital Lahore. Period: $1^{\text {st }}$ March 2019 to $31^{\text {st }}$ August 2019 (6 months). Material \& Methods: Blood sample of fifty female individuals were taken after twelve hours of fasting which were divided into two groups obese type two diabetes mellitus patients having BMl> twenty eight and lean type two diabetes mellitus patients. For measurement of ghrelin concentrations, blood samples collected in specialized EDTA-aprotinin chilled test tubes were immediately centrifuged at two hundreds rpm and their acidification with $1 \mathrm{~mol} / \mathrm{L} \mathrm{HCl}(10 \%$ of sample volume) done to adjust $\mathrm{pH}$ four to preserve plasma acylated ghrelin. The serum was stored at $-20 \mathrm{c}$ for hormonal assay of Ghrelin by Elisa kit of Biovender Laboratani of Czek Republic. Result: The statistical analysis of Acylated ghrelin concentration was done by using paired t-test and one way ANOVA showing significant difference between the concentration of ghrelin in both obese and lean with reference to BMI having P-value $<0.0001$. Conclusions: The study showed that acylated ghrelin levels were comparative on the lower side in obese type two DM as compared to lean type two DM with significant P-value $<0.0001$ by using two-tailed P-value.

Key words: $\quad$ Acylated Ghrelin, BMI, Diabetes Mellitus, Glucose, Insulin.

\section{INTRODUCTION}

In modern world obesity and diabetes mellitus are major health issues which affect these days almost every culture and racial civilization specially the underdeveloped countries and putting huge burden on their health care systems. ${ }^{1}$ Diabetes mellitus is a group of metabolic diseases presented by chronically high level of glucose because of problem in insulin secretion by beta cells of pancreas and resistance to its action on target tissues especially skeletal muscles, adipocytes and to a lesser extent liver. These defects are usually found at insulin receptors levels, its signal transmission system and effectors enzymes or genes which caused unusual metabolic changes in carbohydrates, lipids, and proteins metabolism.2 Obesity which is due to imbalance in caloric intake and energy expenditure, results in excess lipids store in adipocytes. When fat cells become thoroughly soaked, lipids begin to assemble inside heptocytes and muscles that make them insulin resistant lead to pancreatic cell secretion insufficient and make susceptible to type 2 diabetes mellitus. ${ }^{3}$

In 1999, Masayasu and Kangawa with their colleagues extracted and pruified the gastrointestinal peptide hormone named ghrelin from rat stomach, which act as the endogenic substance for the growth hormone secretagogue receptor (GHSR)1a., This gastric hormone acts on anterior pituitary gland and facilities the release of growth hormon. ${ }^{4}$ In 2000, Mark Heiman and Matthias Tschöp found that hormone named ghrelin regulates food intake via acting on brain, glucose metabolism, body weight and adiposity. ${ }^{5}$ 
Within gastric oxyntic glands appetite stimulant hormone named Ghrelin produced by X/Alike cells into two forms: active form (acylated ghrelin) and inactive form (des-acyl ghrelin). For biological actions of it, its convert after synthesis by adding fatty acid octanyl group preferably C8:or C10, on 3rd N-terminal amino acid position, which is a serine. ${ }^{6}$ The protein coding gene, membrane bound O-acyltransferase 4 (MBOAT4), is vital in the activation of ghrelin and located on chromosome 8 and which transcribes an only known post translationally acylate ghrelin enzyme protein called as ghrelin O-acyltransferase (GOAT). ${ }^{7}$ Ghrelin binding with seven transmembrane $G$ protein-coupled receptor i.e GHSR1 promotes most of its neurological actions. GHSR1a is localized in feeding center neurons of hypothalamus that secretes food stimulating neuropeptide $Y$ and Agouti related peptide. GHSR1 present in two forms, GHSR1a which is mediating most of metabolic effects and a truncated form GHSR $1 b .{ }^{8}$ Besides that for appetite amplify actions of ghrelin, it also require the activation of hypothalamic sirtuin-1 (SIRT1) / p53, AMP-activated protein kinase and mammalian target of rapamycin pathways and these ultimately increase food intake..$^{9,10}$ The prefect cannabinoids signaling pathway is also required for activation of AMPK signaling pathway for effect of ghrelin on appetite. ${ }^{11,12}$ On one side ghrelin increases the activity of these neurons whereas on the other hand it inhibits neurons that express proopiomelanocortin food satiety neuropeptide. ${ }^{13,14}$ The importance of this hypothalamic melanocortinergic system is highlighted by fact that in mice lack of Npy and Agrp neuropeptides or their block fails to increases food intake. ${ }^{15,16}$

The glucose regulation role of ghrelin is supported by fact that if GOAT is inhibited pharmacologically it would prevent fall in blood glucose level during utmost spell of calorie restriction, improves the glucose level control and increase release of insulin amount. ${ }^{17,18}$ Ghrelin secretion increases in undulating fashion before taking meal infasting and decreases after feeding. ${ }^{19,5}$ This acute increase in ghrelin level is recommending that it might act as a sign for meal anticipation concerned with meal timing instead of starting eating..$^{20}$ When ghrelin administrated both centrally and peripherally in rats, it initiates intake of food, decreases vitality causing increase in body weight. ${ }^{21,13,22,5,23}$ Similar increase in craving and intake of food after intravenously administration of ghrelin in human seems. ${ }^{23}$ Ghrelin release from gastric tissues crossing the blood-brain barrier reaches brain and initiates appetite by central and peripheral pathways. ${ }^{24,25}$ Whereas centrally synthesized ghrelin activates arcuate nucleus, paraventricular nucleus, dorsomedial region, central nucleus of amygdala, and the nucleus of solitary tract in the hypothalamus and resultant in food intake. ${ }^{26,27,24}$

Inhibition of insulin secretion by ghrelin is mediated through Gai-dependent GHSR1a signaling of the beta-cells and it also involves interaction with the somatostatin receptor subtype-5 (SST5). ${ }^{17,28}$ Despite the fact that inhibitory response among ghrelin and insulin recommends the converse connection between the two however relying upon test conditions, ghrelin at low level may inhibitory affect insulin discharge and a stimulatory impact at high level. ${ }^{29,30,31,32,33}$ Various clinical investigations recommended the opposite relation between ghrelin and insulin in glucose level regulation that when ghrelin administer the plasma level of glucose increases and insulin level decreases. ${ }^{29}$ This relationship is additionally emphasized in restorative examinations between ghrelin, impaired glucose resilience and insulin resistance The blocking role of ghrelin on insulin secretion is additionally upheld in clinical preliminaries where a single intravenous dose of ghrelin elevated the glucose plasma levels in lean and obese patients follow by fall in fasting insulin levels. ${ }^{19,34,5}$ Hence in the light of pervious notion it was observed in clinical study that plasma ghrelin concentration as predictor for type 2 diabetes was decreased in the healthy offspring of these diseases' subjects. Whereas there were compensatory high insulin secretions because of insulin resistance which significantly reduced ghrelin concentrations in type 2 diabetes patients. Also, in various model trials significant difference was observed even by considering age, sex and BMI of subjects that patients with diabetes type 2 have lower fasting total ghrelin plasma level as compared to subjects 
without diabetes type $2 .^{34}$

\section{MATERIAL \& METHODS}

Sampling was done from the endocrinology outdoor patient department of the General hospital and Sheikh Zayad hospital Lahore after the Informed consent from the Obese and lean female patients having Diabetes Mellitus type two which included their basic information plus their height weight and waist measurements for BMI. The both groups had equal numbers i.e twenty five in each groups. The inclusion criteria was Obese newly diagnosed type two DM female BMI $>$ twenty eight and Lean newly diagnosed type two DM Female. Whereas the exclusion criteria were any gastrointestinal disease or cachectic states such as cancer, thyroid disease, liver disease, or infection, patients with renal impairment, patients of DM more than one year or using any Diet or Medicine interfere with carbohydrates metabolism.

Blood sample of fifty female individuals were taken after twelve hours of fasting which were divided into two groups obese type two diabetes mellitus patients having BMI > twenty eight and lean type two diabetes mellitus patients. For measurement of ghrelin concentrations, blood samples collected in specialized EDTA-aprotinin chilled test tubes were immediately centrifuged at two hundreds rpm and their acidification with 1 $\mathrm{mol} / \mathrm{L} \mathrm{HCl}$ (10\% of sample volume) done to adjust $\mathrm{pH}$ four to preserve plasma acylated ghrelin. The serum was stored at -20c for hormonal assay of Ghrelin. Eliza kit for the test of Acylated ghrelin was brought from Biovender Co from Czek Republic and specialized test tubes brought from Fsicher Scientific Co from UK.

Study had been conducted after the approval of synopsis by the technical review committee of UOL. The experimental protocol was approved by the Research Ethical Committee of University of Lahore.

\section{RESULT}

The statistical analysis of Acylated ghrelin concentration was confirmed on absorbance 405 by using paired t-test and one-way ANOYA. In the Figure- 1 show the standard curve of ghrelin concentration at 405 absorbance and R2 value near to 1 whereas the valued concentration of ghrelin has shown in Table-I. The concentration of ghrelin in obese and lean type 2 diabetes mellitus with comparison to BMI had been shown in the Table-II\&III respectively.

Using paired t-test on the concentration of acylated ghrelin between obese and lean type 2 diabetes mellitus groups had shown that P-value $<0.0001$ which shows significant difference between the concentration of ghrelin both obese and lean with reference to $\mathrm{BMI}$ as shown in Figure-2.

Also, when paired t-test was applied on the BMI of the Lean and obese type 2 diabetes mellitus significant difference $\mathrm{P}$-value $<0.0001$ that less than $<0.5$ observed as shown in Figure-3.

The association between age, BMl and concentration of ghrelin in lean Type 2 DM was shown significant $p$-value 0.0001 when one-way ANOVA was applied in Figure-4.

In the Figure-5, the comparison between age, $\mathrm{BMI}$ and concentration of ghrelin in obese type 2 DM had shown significant P-value $<0.00001$ when one-way ANOVA is applied.

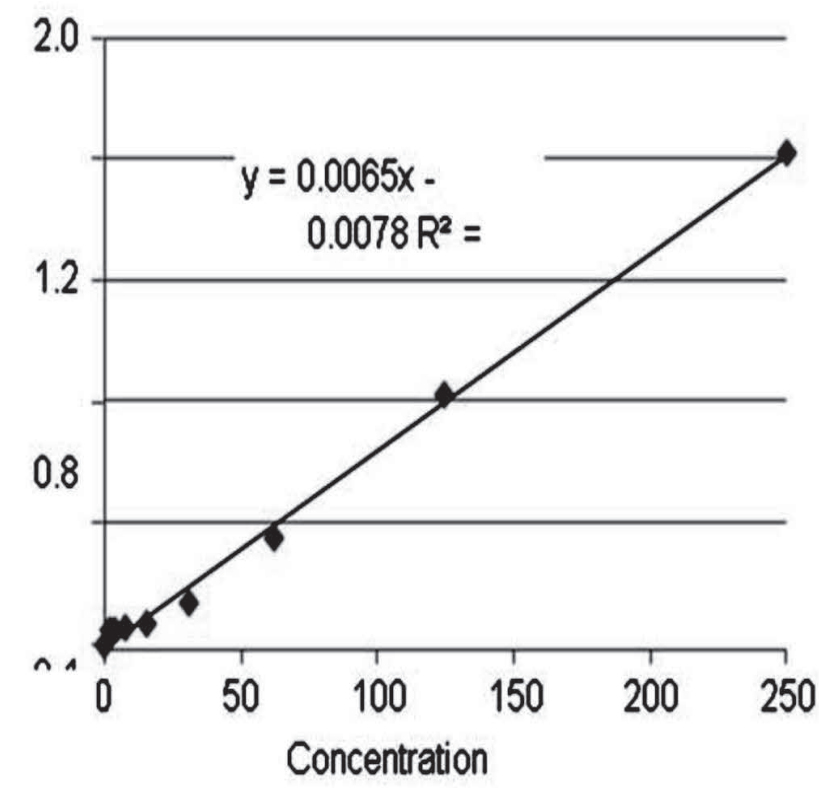

Figure-1 


\begin{tabular}{|c|c|c|c|c|}
\hline Sample & $\begin{array}{c}\text { Sample_ } \\
\text { abs }\end{array}$ & Abs-Blank & conc & $\begin{array}{l}\text { Conc. } \\
\text { (pg/mL) }\end{array}$ \\
\hline 1 & 0.265 & 0.041 & 7.51 & 15.02 \\
\hline 2 & 0.272 & 0.048 & 8.58 & 17.17 \\
\hline 3 & 0.27 & 0.046 & 8.28 & 16.55 \\
\hline 4 & 0.26 & 0.036 & 6.74 & 13.48 \\
\hline 5 & 0.266 & 0.042 & 7.66 & 15.32 \\
\hline 6 & 0.264 & 0.040 & 7.35 & 14.71 \\
\hline 7 & 0.268 & 0.044 & 7.97 & 15.94 \\
\hline 8 & 0.274 & 0.050 & 8.89 & 17.78 \\
\hline 9 & 0.261 & 0.037 & 6.89 & 13.78 \\
\hline 10 & 0.282 & 0.058 & 10.12 & 20.25 \\
\hline 11 & 0.263 & 0.039 & 7.20 & 14.40 \\
\hline 12 & 0.262 & 0.038 & 7.05 & 14.09 \\
\hline 13 & 0.254 & 0.030 & 5.82 & 11.63 \\
\hline 14 & 0.274 & 0.050 & 8.89 & 17.78 \\
\hline 15 & 0.272 & 0.048 & 8.58 & 17.17 \\
\hline 16 & 0.278 & 0.054 & 9.51 & 19.02 \\
\hline 17 & 0.276 & 0.052 & 9.20 & 18.40 \\
\hline 18 & 0.275 & 0.051 & 9.05 & 18.09 \\
\hline 19 & 0.271 & 0.047 & 8.43 & 16.86 \\
\hline 20 & 0.263 & 0.039 & 7.20 & 14.40 \\
\hline 21 & 0.246 & 0.022 & 4.58 & 9.17 \\
\hline 22 & 0.262 & 0.038 & 7.05 & 14.09 \\
\hline 23 & 0.266 & 0.042 & 7.66 & 15.32 \\
\hline 24 & 0.271 & 0.047 & 8.43 & 16.86 \\
\hline 25 & 0.26 & 0.036 & 6.74 & 13.48 \\
\hline 26 & 0.266 & 0.042 & 7.66 & 15.32 \\
\hline 27 & 0.265 & 0.041 & 7.51 & 15.02 \\
\hline 28 & 0.26 & 0.036 & 6.74 & 13.48 \\
\hline 29 & 0.252 & 0.028 & 5.51 & 11.02 \\
\hline 30 & 0.253 & 0.029 & 5.66 & 11.32 \\
\hline 31 & 0.265 & 0.041 & 7.51 & 15.02 \\
\hline 32 & 0.281 & 0.057 & 9.97 & 19.94 \\
\hline 33 & 0.282 & 0.058 & 10.12 & 20.25 \\
\hline 34 & 0.265 & 0.041 & 7.51 & 15.02 \\
\hline 35 & 0.262 & 0.038 & 7.05 & 14.09 \\
\hline 36 & 0.252 & 0.028 & 5.51 & 11.02 \\
\hline 37 & 0.248 & 0.024 & 4.89 & 9.78 \\
\hline 38 & 0.258 & 0.034 & 6.43 & 12.86 \\
\hline 39 & 0.293 & 0.069 & 11.82 & 23.63 \\
\hline 40 & 0.273 & 0.049 & 8.74 & 17.48 \\
\hline 41 & 0.259 & 0.035 & 6.58 & 13.17 \\
\hline 42 & 0.26 & 0.036 & 6.74 & 13.48 \\
\hline 43 & 0.265 & 0.041 & 7.51 & 15.02 \\
\hline 44 & 0.262 & 0.038 & 7.05 & 14.09 \\
\hline 45 & 0.273 & 0.049 & 8.74 & 17.48 \\
\hline 46 & 0.25 & 0.026 & 5.20 & 10.40 \\
\hline 47 & 0.252 & 0.028 & 5.51 & 11.02 \\
\hline 48 & 0.249 & 0.025 & 5.05 & 10.09 \\
\hline 49 & 0.259 & 0.035 & 6.58 & 13.17 \\
\hline 50 & 0.263 & 0.039 & 7.20 & 14.40 \\
\hline
\end{tabular}

\begin{tabular}{|c|c|c|}
\hline Serial No & BMI & Ghrelin Conc \\
\hline 01. & 30 & 14.85 \\
\hline 02. & 31 & 13.46 \\
\hline 03. & 45 & 13.94 \\
\hline 04. & 38 & 13.64 \\
\hline 05. & 42 & 13.94 \\
\hline 06. & 45 & 13.94 \\
\hline 07. & 26 & 11.82 \\
\hline 08. & 35 & 14.55 \\
\hline 09. & 26 & 10 \\
\hline 10. & 29 & 13.94 \\
\hline 11. & 29 & 14.85 \\
\hline 12. & 35 & 13.64 \\
\hline 13. & 36 & 14.24 \\
\hline 14. & 33 & 13.03 \\
\hline 15. & 44 & 15.15 \\
\hline 16. & 42 & 14.55 \\
\hline 17. & 34 & 11.52 \\
\hline 18. & 38 & 13.33 \\
\hline 19. & 40 & 14.24 \\
\hline 20. & 28 & 11.52 \\
\hline 21. & 36 & 14.24 \\
\hline 22. & 34 & 11.52 \\
\hline 23. & 28 & 10.61 \\
\hline 24. & 34 & 14.4 \\
\hline 25. & 26 & 11.21 \\
\hline AVERAGE & 34.56 & 13.2852 \\
\hline
\end{tabular}

Table-II. BMI and ghrelin concentration in obese type 2 DM Patients

\begin{tabular}{|c|c|c|}
\hline Serial no & BMI & Ghrelin Conc \\
\hline 1. & 24 & 15.45 \\
\hline 2. & 20 & 16.67 \\
\hline 3. & 21 & 16.06 \\
\hline 4. & 25 & 16.97 \\
\hline 5. & 23 & 15.45 \\
\hline 6. & 24 & 17.27 \\
\hline 7. & 24 & 16.36 \\
\hline 8. & 25 & 17.88 \\
\hline 9. & 23 & 18.79 \\
\hline 10. & 23 & 18.18 \\
\hline 11. & 24 & 16.06 \\
\hline 12. & 23 & 17.56 \\
\hline 13. & 22 & 16.06 \\
\hline 14. & 19 & 26.97 \\
\hline 15. & 24 & 19.39 \\
\hline 16. & 25 & 18.44 \\
\hline 17. & 25 & 18.18 \\
\hline 18. & 24 & 19.91 \\
\hline 19. & 20 & 20 \\
\hline 20. & 22 & 21.97 \\
\hline 21. & 23 & 20.79 \\
\hline 22. & 22 & 20.5 \\
\hline 23. & 21 & 23.44 \\
\hline 24. & 20 & 20.21 \\
\hline 25. & 19 & 30.21 \\
\hline AVERAGE & 22.6 & 19.1508 \\
\hline
\end{tabular}

Table-III. BMI and ghrelin concentration in lean type 2 Table-I. Concentration of ghrelin in all patients 
Comparsion between Conc of Ghrelin in Obese and Lean

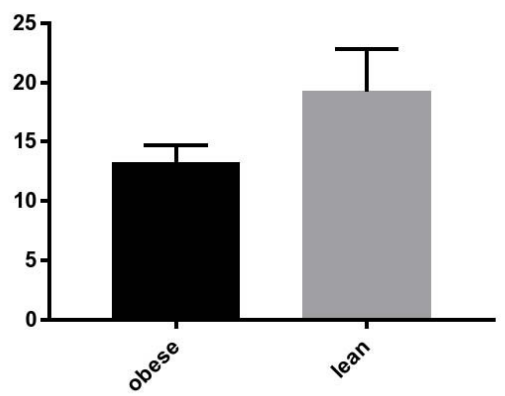

Figure-2

\section{Comparsion between BMI of lean and obese}

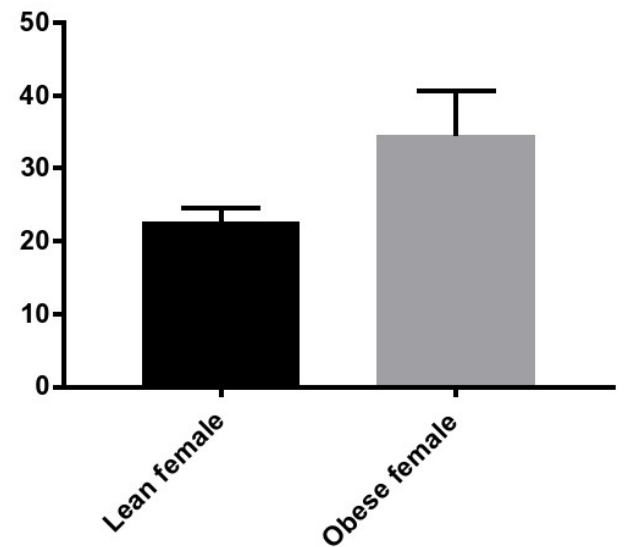

Figure-3.

\section{DISCUSSION}

The study was designed to testify the hypothesis that acylated ghrelin level was lower in obese diabetes mellitus type 2 as compared to lean type 2 Diabetes Mellitus. During the research acylated ghrelin levels in obsess found to be on the lower side as compared to lean patients with significant $P$-value $<0.0001$ which shown significant difference by using two-tailed P-value. In line above mention theory, their study had also demonstrated that acylated ghrelin levels in subjects of their earlier stages of diabetes was lower as compared to develop full spectrum of the diseases also first degree relatives of these patients who had normal glucose level, had lower levels of active ghrelin as compared to normal people. Whereas acylated ghrelin levels were more associated with body mass index and abdominal girth rather than with high glucose level. ${ }^{35} \mathrm{BMI}$, abdominal circumference and levels of ghrelin
Comparsion of Age,BMI and Conc of Ghrelin in Obese

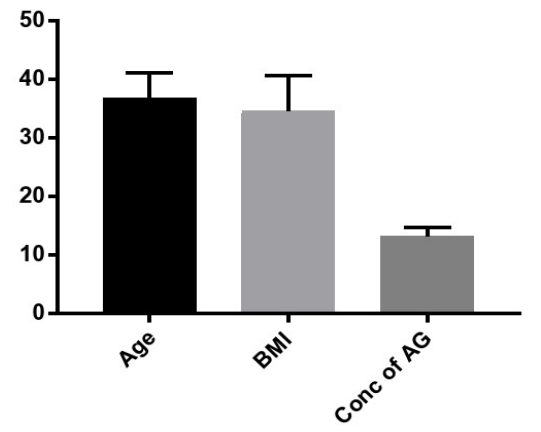

Figure-4.

\section{Comparsion of Age,BMI and Conc of Ghrelin in Obese}

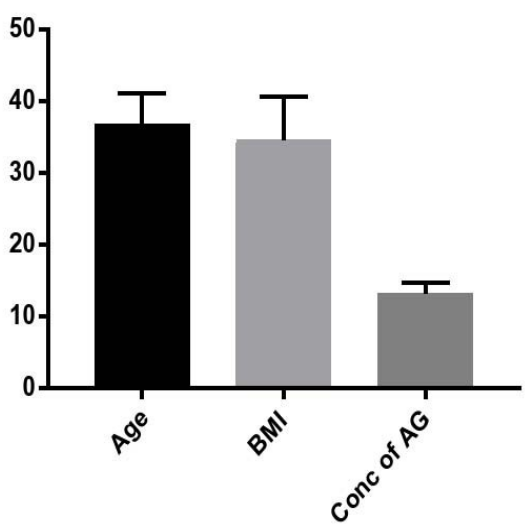

Figure-5.

had inverse relation each other as reported in their study. ${ }^{36}$ Edrmann with his colleagues found that subjects with normal glucose level but obese had high ghrelin concentration as compared to those subjects which were obese but high glucose level. ${ }^{37}$ Their study found that levels of ghrelin were on lower side in patients with full spectrum of diabetes mellitus and these levels were inversely proportional to the glucose blood level. ${ }^{38}$

They discovered ghrelin amount in subjects having type 2diabetes lower than those of subjects without type 2diabetes. Hence that could be lower because of their higher adiposity. ${ }^{39}$ They showed that low plasma ghrelin levels were associated with type 2 diabetes mellitus and insulin resistance. Ghrelin levels were correlated with insulin resilience markers such as body weight, fasting blood insulin level and the HOMA-IR index 
in healthy controls. Although the sample size was small healthy peoples have high active ghrelin amount as compared to diabetes type 2 subjects after correction for age differences between the study groups. A similar relation was observed and reported among Finnish participants in the Oulu Project Elucidating Risk of Atherosclerosis study. 40

Likewise they discovered that fasting levels of ghrelin in normal subjects and patients with anorexia nervosa, straightforward stoutness, or type 2 diabetes mellitus associated contrarily with $\mathrm{BMI}$ inside each groups. ${ }^{41}$

\section{CONCLUSION}

The study showed that acylated ghrelin levels were comparative on the lower side in obese type two DM as compared to lean type two DM with significant $\mathrm{P}$-value $<0.0001$ by using two-tailed P-value.

Copyright@ 05 Mar, 2020.

\section{REFERENCES}

1. Anne-Laure Pohera, Matthias H. Tschöpa,b , Timo D. Müllera, et al. Ghrelin regulation of glucose metabolism Peptides 2013;100, 236-242.

2. Akram $T$ Kharroubi and Hisham M Darwish, et al. Diabetes mellitus: The epidemic of the century World $\mathrm{J}$ Diabetes 2015: June 25; 6(6): 850-867.

3. Neary MT, Batterham RL. Gut hormones, implications for the treatment of obesity. Pharmacol Ther 2009; 124: 44-56.

4. Kojima, M., Hosoda, H., Date, Y., Nakazato, M., Matsuo, $\mathrm{H}$., Kangawa, K, et al. Ghrelin is a growth-hormonereleasing acylated peptide from stomach. Nature 1999; 402:656e660.

5. Tschöp M, Smiley DL, Heiman ML. Ghrelin induces adiposity in rodents. Nature. 2000 Oct;407(6806):90813.

6. J.A. Gutierrez, P.J. Solenberg, D.R. Perkins, J.A. Willency, M.D. Knierman, Z. Jin, et al. Ghrelin octanoylation mediated by an orphan lipid transferase, Proc. Natl. Acad. Sci. U. S. A. 2008; 105: 6320-6325.
7. Barnett BP, Hwang Y, Taylor MS, Kirchner H, Pfluger PT, Bernard V, Lin YY, Bowers EM, Mukherjee C, Song WJ, Longo PA. Glucose and weight control in mice with a designed ghrelin 0-acyltransferase inhibitor. Science. 2010 Dec 17;330(6011):1689-92.

8. Angelidis G, Valotassiou V, Georgoulias P, et al. Current and potential roles of ghrelin in clinical practice. $J$ Endocrinol Invest 2010. 33: 823-38.

9. Willesen MG, Kristensen P, Rømer J. Co-localization of growth hormone secretagogue receptor and NPY mRNA in the arcuate nucleus of the rat. Neuroendocrinology. 1999;70(5):306-16.

10. Chen HY, Trumbauer ME, Chen AS, Weingarth DT, Adams JR, Frazier EG, Shen Z, Marsh DJ, Feighner SD, Guan XM, Ye Z. Orexigenic action of peripheral ghrelin is mediated by neuropeptide $\mathrm{Y}$ and agouti-related protein. Endocrinology. 2004 Jun 1;145(6):2607-12.

11. van Thuijl $H$, Kola $B$, Korbonits $M$. Appetite and metabolic effects of ghrelin and cannabinoids: involvement of AMP-activated protein kinase. Vitamins \& Hormones. 2007 Jan 1;77:121-48.

12. B. Kola and M. Korbonits. "Shedding light on the intricate puzzle of ghrelin's effects on appetite regulation," Journal of Endocrinology 2009:vol. 202, no. 2, pp. 191-198.

13. Nakazato M, Murakami N, Date $\mathrm{Y}$, Kojima M, Matsuo $\mathrm{H}$, Kangawa $\mathrm{K}$, Matsukura S. A role for ghrelin in the central regulation of feeding. Nature. 2001 Jan;409(6817):194-8.

14. K.P. Skibicka, C. Hansson, E. Egecioglu, S.L. Dickson, et al. Role of ghrelin in food reward: Impact of ghrelin on sucrose self-administration and mesolimbic dopamine and acetylcholine receptor gene expression, Addict. Biol. 2012; 17 95-107.

15. Kalra SP, Ueno N, Kalra PS. Stimulation of appetite by ghrelin is regulated by leptin restraint: peripheral and central sites of action. The Journal of nutrition. 2005 May 1;135(5):1331-5.

16. Druce MR, Wren AM, Park AJ, Milton JE, Patterson M, Frost G, Ghatei MA, Small C, Bloom SR. Ghrelin increases food intake in obese as well as lean subjects. International journal of obesity. 2005 Sep;29(9):1130-6.

17. Dezaki K, Sone H, Koizumi M, Nakata M, Kakei M, Nagai H, Hosoda H, Kangawa K, Yada T. Blockade of pancreatic islet-derived ghrelin enhances insulin secretion to prevent high-fat diet-induced glucose intolerance. Diabetes. 2006 Dec 1;55(12):3486-93. 
18. Chuang JC, Sakata I, Kohno D, Perello M, OsborneLawrence S, Repa JJ, Zigman JM. Ghrelin directly stimulates glucagon secretion from pancreatic a-cells. Molecular Endocrinology. 2011 Sep $1 ; 25(9): 1600-11$.

19. 41. D.E. Cummings, J.Q. Purnell, R.S. Frayo, K. Schmidova, B.E. Wisse, D.S. Weigle A et al. Preprandial rise in plasma ghrelin levels suggests a role in meal initiation in humans, Diabetes 2001: 50 1714-1719.

20. Frecka JM, Mattes RD. Possible entrainment of ghrelin to habitual meal patterns in humans. American Journal of Physiology-Gastrointestinal and Liver Physiology. 2008 Mar;294(3):G699-707.

21. Kamegai J, Tamura $H$, Shimizu T, Ishii S, Sugihara $H$, Wakabayashi I. Chronic central infusion of ghrelin increases hypothalamic neuropeptide $Y$ and Agoutirelated protein mRNA levels and body weight in rats. Diabetes. 2001 Nov 1;50(11):2438-43.

22. Shintani M, Ogawa $Y$, Ebihara $K$, Aizawa-Abe $M$, Miyanaga F, Takaya K, Hayashi T, Inoue G, Hosoda K, Kojima M, Kangawa K. Ghrelin, an endogenous growth hormone secretagogue, is a novel orexigenic peptide that antagonizes leptin action through the activation of hypothalamic neuropeptide $\mathrm{Y} / \mathrm{Y} 1$ receptor pathway. Diabetes. 2001 Feb 1;50(2):227-32.

23. Wren AM, Seal LJ, Cohen MA, Brynes AE, Frost GS, Murphy KG, Dhillo WS, Ghatei MA, Bloom SR. Ghrelin enhances appetite and increases food intake in humans.Journal of Clinical Endocrinology and Metabolism, 2001: vol. 86, no. 12, pp. 5992- 5995.

24. Cowley MA, Smith RG, Diano S, Tschöp M, Pronchuk N, Grove KL, Strasburger CJ, Bidlingmaier M, Esterman M, Heiman ML, Garcia-Segura LM. The distribution and mechanism of action of ghrelin in the CNS demonstrates a novel hypothalamic circuit regulating energy homeostasis. Neuron. 2003 Feb 20;37(4):64961.

25. Venkova K, Greenwood-Van Meerveld B. Application of ghrelin to gastrointestinal diseases. Current opinion in investigational drugs (London, England: 2000). 2008 Oct;9(10):1103.

26. Mano-Otagiri A, Ohata $H$, Iwasaki-Sekino $A$, Nemoto T, Shibasaki T. Ghrelin suppresses noradrenaline release in the brown adipose tissue of rats. Journal of Endocrinology. 2009 Jun 1;201(3):341.

27. Olszewski PK, Li D, Grace MK, Billington CJ, Kotz CM, Levine AS. Neural basis of orexigenic effects of ghrelin acting within lateral hypothalamus. Peptides. 2003 Apr 1;24(4):597-602.
28. S. Park, H. Jiang, H. Zhang, R.G. Smith, et al. Modification of ghrelin receptor signaling by somatostatin receptor-5 regulates insulin release, Proc. Natl. Acad. Sci. U. S. A. 2012; 109 19003-19008.

29. 40.F. Broglio, C. Gottero, A. Benso, F. Prodam, S. Destefanis, C. Gauna, et al. Effects of ghrelin on the insulin and glycemic responses to glucose arginine, or free fatty acids load in humans, J. Clin. Endocrinol. Metab. 2003; 88 4268-4272.

30. E. Adeghate, A.S. Ponery Ghrelin stimulates insulin secretion from the pancreas of normal and diabetic rats, J. Neuroendocrinol. 2002; 14 555-560.

31. Lee HM, Wang G, Englander EW, Kojima M, Greeley Jr GH. Ghrelin, a new gastrointestinal endocrine peptide that stimulates insulin secretion: enteric distribution, ontogeny, influence of endocrine, and dietary manipulations. Endocrinology. 2002 Jan 1;143(1):185-90.

32. Colombo M, Gregersen S, Xiao J, Hermansen K. Effects of ghrelin and other neuropeptides (CART, $\mathrm{MCH}$, orexin A and B, and GLP-1) on the release of insulin from isolated rat islets. Pancreas. 2003 Aug $1 ; 27(2): 161-6$.

33. Salehi A, de la Cour CD, Håkanson R, Lundquist I. Effects of ghrelin on insulin and glucagon secretion: a study of isolated pancreatic islets and intact mice. Regulatory peptides. 2004 May 15;118(3):143-50.

34. 45/D.E. Flanagan, M.L. Evans, T.P. Monsod, F. Rife, R.A. Heptulla, W.V. Tamborlane, et al. The influence of insulin on circulating ghrelin, Am. J. Physiol. Endocrinol. Metab 2003; 284 E313-6.

35. Sharifi F, Yamini M, Esmaeilzadeh A, Mousavinasab N, Shajari Z. Acylated ghrelin and leptin concentrations in patients with type 2 diabetes mellitus, people with prediabetes and first degree relatives of patients with diabetes, a comparative study. Journal of Diabetes \& Metabolic Disorders. 2013 Dec 1;12(1):51. http://www. jdmdonline.com/content/12/1/51.

36. Monti V, Carlson JJ, Hunt SC, Adams TD. Relationship of ghrelin and leptin hormones with body mass index and waist circumference in a random sample of adults. Journal of the American Dietetic Association. 2006 Jun 1;106(6):822-8.

37. Edmann J, Lipple F, Wagenpfeil S, et al.,: Differential association of basal and postprandial plasma ghrelin with leptin, insulin, and type 2 diabetes. Diabetes 2005. 55:8-137. 
38. Pöykkö SM, Kellokoski E, Hörkkö S, Kauma H, Kesäniemi YA, Ukkola O. Low plasma ghrelin is associated with insulin resistance, hypertension, and the prevalence of type 2 diabetes. Diabetes. 2003 Oct 1;52(10):254653.

39. Eizadi M, Dooaly H, Seyedhoseini MA, Khorshidi European Journal of Experimental Biology, 2011; 1 (4):202-205.
40. Al Qarni AA, Joatar FE, Das N, Awad M, Eltayeb M, AlZubair AG, Ali ME, Al Masaud A, Shire AM, Gumaa K, Giha HA. Association of plasma ghrelin levels with insulin resistance in type 2 diabetes mellitus among Saudi subjects. Endocrinology and Metabolism. 2017 Jun $1 ; 32(2): 230-40$.

41. Tomomi Shiiya, Masamitsu Nakazato, Masanari Mizuta, Yukari Date, Muhtashan S. Mondal, Muneki Tanaka, SHIN-ICHI Nozoe, Hiroshi Hosoda, Kenji Kangawa, and Shigeru Matsukura, et al. Plasma ghrelin levels in lean and obese humans and the effect of glucose on ghrelin secretion, The Journal of Clinical Endocrinology \& Metabolism(2002); 87(1):240-244.

\begin{tabular}{|c|c|c|c|}
\hline \multicolumn{4}{|c|}{ AUTHORSHIP AND CONTRIBUTION DECLARATION } \\
\hline Sr. \# & Author(s) Full Name & Contribution to the paper & Author(s) Signature \\
\hline 1 & Zaheer Iqbal Sheikh & 1st Author & \\
\hline 2 & Amna Rashid Tariq & 2nd Author & \\
\hline 3 & Amer Shoaib & 3rd Author & \\
\hline 4 & Saeed Mahmood & 4th Author & \\
\hline
\end{tabular}

